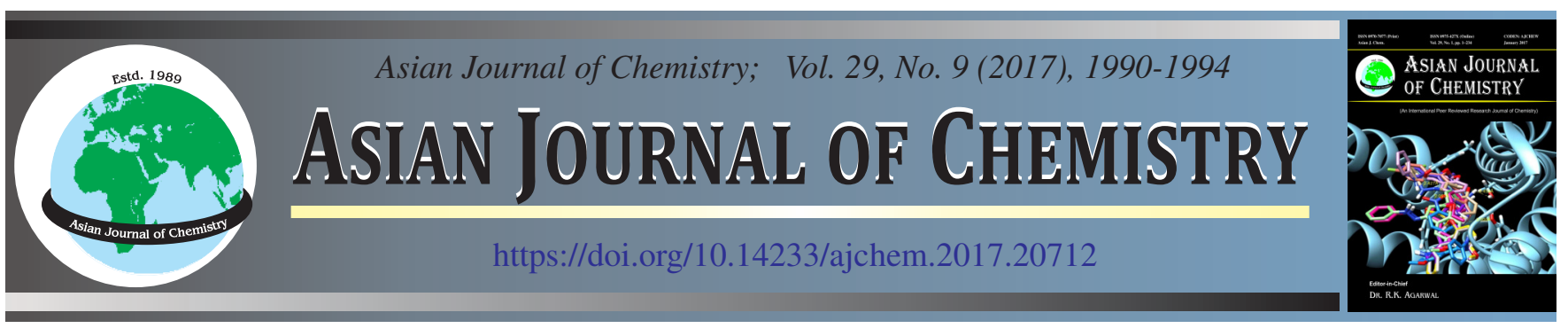

\title{
Characterization of Doped and Undoped Tin Oxide Thin Films Prepared by Sol Gel Spin Coating Technique
}

\author{
AMANDEEP KAUR* and RAJESh Kumar
}

Department of Physics, Lovely Professional University, Phagwara-144 411, India

*Corresponding author: E-mail: amandeepkchak@gmail.com

\begin{abstract}
Optical and structural characterization of $\mathrm{Cu}$-doped and pure $\mathrm{SnO}_{2}$ thin films were performed as a part of this investigation. In this respect, the effects of changing the concentration of the precursors on the thin film properties were investigated. Tin dioxide thin films both in pure and doped form were prepared by a sol gel spin coating technique. The metallic oxide $\left(\mathrm{SnO}_{2}\right)$ films deposited were characterized using the UV Spectrophotometer and XRD studies. The average band gap for tin dioxide thin films was found to be approximately $3.80 \mathrm{eV}$. As far as direct band gap is concerned that copper doping appears to have no effect on the direct band gap which is in accordance with the literature. The indirect band gap for thin films was found to be approximately $3.48,3.32$ and $3.20 \mathrm{eV}$ for different concentrations of the solutions, respectively. The indirect energy gap of the $\mathrm{Cu}$ doped thin films decreases as $3.76,3.73$ and $3.16 \mathrm{eV}$, respectively for different concentrations of the precursor solutions. The less value may be due to the addition of $\mathrm{Cu}$-dopant and may also be due to growth of grain and improvement of the degree of crystallization.
\end{abstract}

Keywords: $\mathrm{SnO}_{2}$ thin films, Spin coating, Band gap, Surface structure.

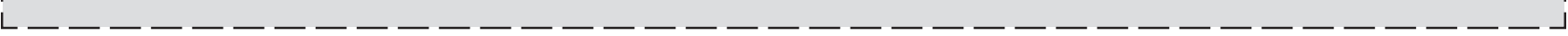

\section{INTRODUCTION}

Thin films are used for variety of applications in different fields of scientific research and investigations nowadays [1-5]. Thin films based on metal oxides are very good materials for different applications [6]. Out of these metal oxides, tin oxide is a wonderful material in the sense that its properties can be tailored by adding suitable impurities in it to suit the particular needs of an application [4]. Tin oxide is a wide band gap n-type semiconductor $(3.6 \mathrm{eV})$ material which shows good transmission properties in the visible region and high reflection in IR region [7-12]. These properties make it a perfect candidate for use in the solar cells and antireflective coatings $[2,13]$. The doped $\mathrm{SnO}_{2}$ owes its properties to the dopant introduced and undoped to the concentration of oxygen vacancies on its surface $[8,11,14]$. Tin oxide thin films have been prepared by a variety of methods by different research investigators since 1962. These methods are reactive thermal evaporation, electron beam evaporation, spray pyrolysis, sputtering, etc. $[15,16]$. These methods are costly and require complicated apparatus. Out of these methods, we have used a cost effective and relatively simple method of thin film preparation, sol gel spin coating $[9,17,18]$. The advantages of this method include low cost, simple and good film morphology of prepared thin films $[7,15,19]$.

\section{EXPERIMENTAL}

Undoped $\mathrm{SnO}_{2}$ thin films: $\mathrm{SnCl}_{2} \cdot 2 \mathrm{H}_{2} \mathrm{O}$ was used as the precursor for the preparation of sol gel. Methanol and glacial acetic acid were used as the solvent and chelating agent for dissolving the precursor material in a beaker. The solution was prepared for different concentrations $0.2,0.4$ and $0.6 \mathrm{M}$, respectively. The stirring of prepared solution was done at room temperature by using magnetic stirrer in order to achieve the transparent and homogeneous solution.

Doped $\mathrm{SnO}_{2}$ thin films: Tin(IV) chloride dihydrate $\left(\mathrm{SnCl}_{2} \cdot 2 \mathrm{H}_{2} \mathrm{O}\right)$ was used as the precursor for the preparation of sol gel. Methanol, copper acetate and glacial acetic acid were used as the solvent and chelating agent for dissolving the precursor material in a beaker. The solution was prepared for different concentrations $0.2,0.4$ and $0.6 \mathrm{M}$, respectively. The stirring of prepared solution was done at room temperature by using magnetic stirrer in order to achieve the transparent and homo-geneous solution

General procedure: The glass substrates were cleaned with cleaning soap, distilled water and acetone in order to remove the solution organic impurities. The cleaned glass substrates were dried in a furnace at $200{ }^{\circ} \mathrm{C}$ for $10 \mathrm{~min}$. After drying, the glass substrates were used for depositing the films from the prepared solution. The film was deposited by the use 
of a spin coater (Apex instruments make) model no. Spin NXGP1. The thin film was deposited on the glass substrates by applying $1 \mathrm{~mL}$ of the solution on the surface of glass substrates. The films were deposited with the spin coater having spin duration for each cycle of $60 \mathrm{~s}$, spin speed of $3000 \mathrm{rpm}$ and acceleration of $2 \mathrm{~m} / \mathrm{s}^{2}$ [6].

Detection method: The optical properties of thin films have been studied from UV spectrographs from a UV-visible spectrophotometer (Model No. UV-1800 Shimadzu) in the wavelength range of $200-800 \mathrm{~nm}$. The structural properties were analyzed by using X-ray diffraction spectra using $\mathrm{CuK}_{\alpha}$ (wavelength $=1.5405 \AA$ ) radiation (model no. $\mathrm{X}^{\prime}$ Pert PRO, PANalytical Netherland).

\section{RESULTS AND DISCUSSION}

The absorbance spectra of thin films with different concentrations are shown in Fig. 1. The trend of absorption spectra is same for all the grown thin films. Absorbance spectra show that the absorbance decreases with the increase in wavelength for all the samples. The absorption decreases almost same for 0.4 and $0.6 \mathrm{M}$ samples whereas it is comparatively greater for $0.2 \mathrm{M}$ sample. This shows that the thickness of 0.2 $\mathrm{M}$ sample is higher than the other samples. Absorption is very high in the UV region, lowest absorbance in the visible region. In the NIR region, absorbance became steady. Absorbance decreases as precursor concentration increases for thin films. The transmittance spectra of films with different concentrations are shown in Fig. 2. The transmittance spectra have the same trend for all the films. The transmittance is highest in the visible region for 0.4 and $0.6 \mathrm{M}$ solutions and is lowest for $0.2 \mathrm{M}$ solution. This is because lower thickness of 0.4 and $0.6 \mathrm{M}$ solution samples. In the NIR region, transmittance became steady. Transmittance increases with the increase in precursor concentrations. The absorption coefficient of $\mathrm{SnO}_{2}$ thin films with different concentrations is shown in Fig. 3. The absorption coefficient $(\alpha)$ of $\mathrm{SnO}_{2}$ thin films were calculated using the following equation:

$$
\alpha=\frac{2.303 \mathrm{~A}}{\mathrm{t}}
$$

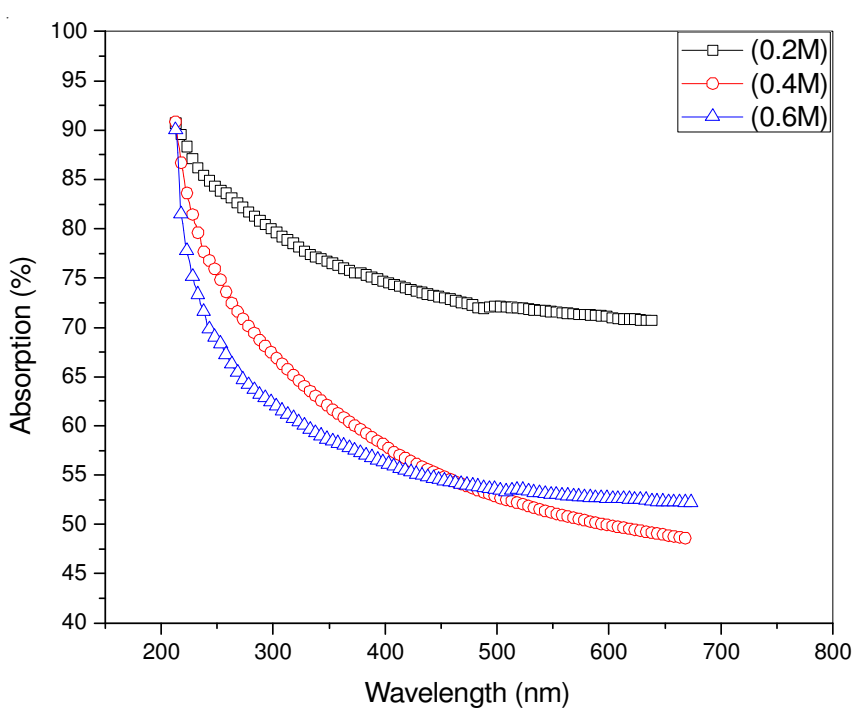

Fig. 1. Absorbance spectra for $\mathrm{SnO}_{2}$ thin films as a function of wavelength

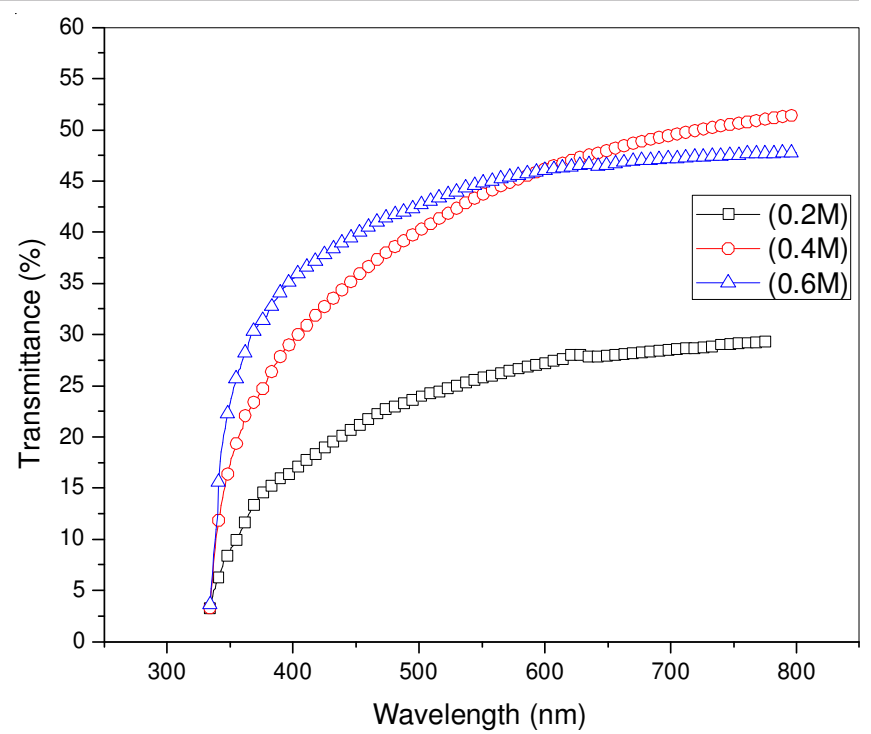

Fig. 2. Transmittance spectra for $\mathrm{SnO}_{2}$ thin films as a function of wavelength

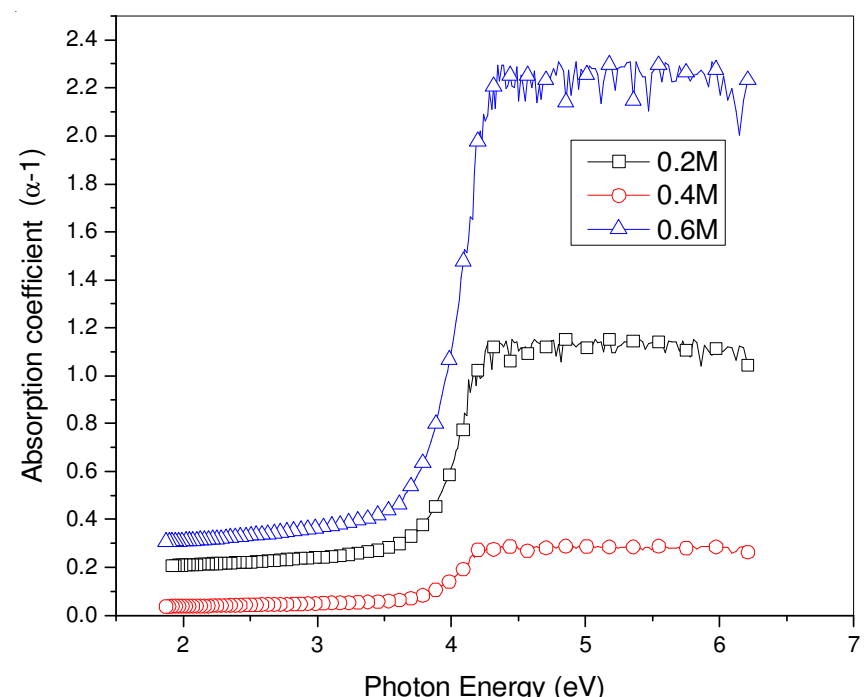

Fig. 3. Absorption coefficient of $\mathrm{SnO}_{2}$ thin films as a function of photon energy

where $\alpha$ is the absorption coefficient, $t$ is the thickness of the film and $\mathrm{A}$ is the absorbance. The thicknesses of thin films have been found to be in the range of $2-10 \mu \mathrm{m}$.

The absorbance coefficient of $\mathrm{SnO}_{2}$ thin film was plotted against the photon energy. The pattern is same for all the films with different concentrations. The films have lower absorption for longer wavelengths; absorption is highest for smaller wavelengths.

The direct and indirect optical band gap energy of thin films was extrapolated from the plot of $(\alpha h f)^{2}$ and $(\alpha h f)^{1 / 2}$ against photon energy $(\mathrm{eV})$ shown in Figs. $4 \mathrm{a}-\mathrm{c}$ and $5 \mathrm{a}-\mathrm{d}$, respectively. The band gap energy values were determined by plotting intercept with energy axis. The direct and indirect band gap energies are affected by precursor concentrations. The direct energy band gaps for thin films were found to be in the range of about $3.77-3.83 \mathrm{eV}$, respectively. These thin films are preferred to be used in optoelectronic devices due to the greater energy difference between valence band and conduction band. The indirect band gap for thin film was found to be approximately 3.48, 3.32 and $3.20 \mathrm{eV}$ for different concentrations of the solutions, respectively. 


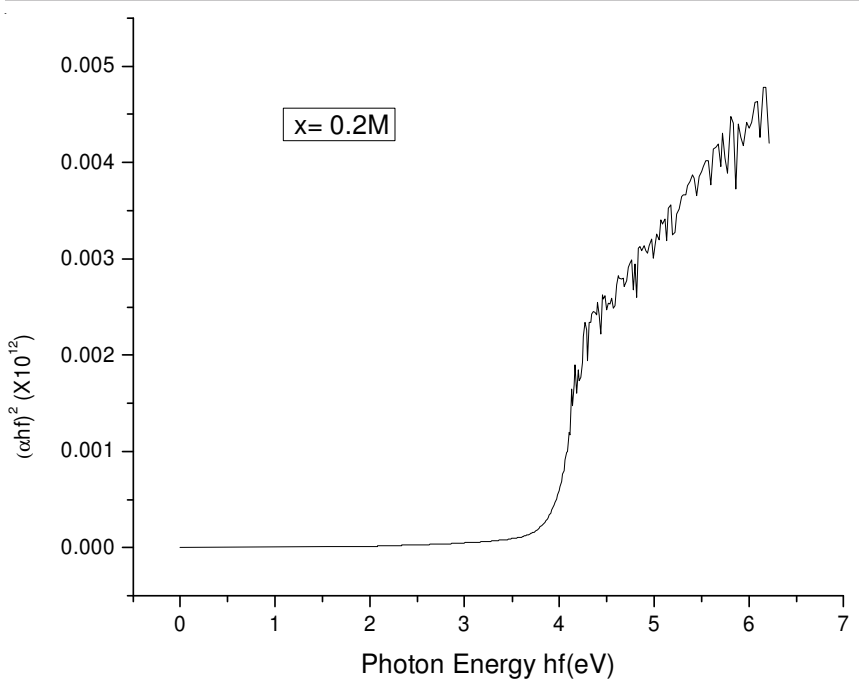

Fig. 4a. Optical energy gap for the direct allowed transition of $\mathrm{SnO}_{2}$ films for the sample prepared by of $0.2 \mathrm{M}$ concentration

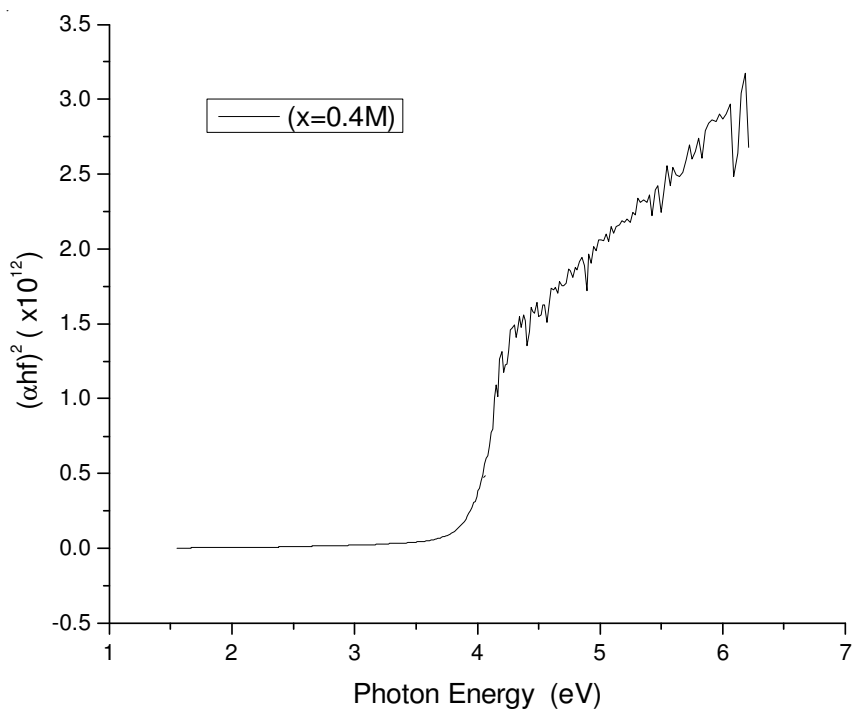

Fig. 4b. Optical energy gap for the direct allowed transition of $\mathrm{SnO}_{2}$ films for the sample prepared by of $0.4 \mathrm{M}$ concentration

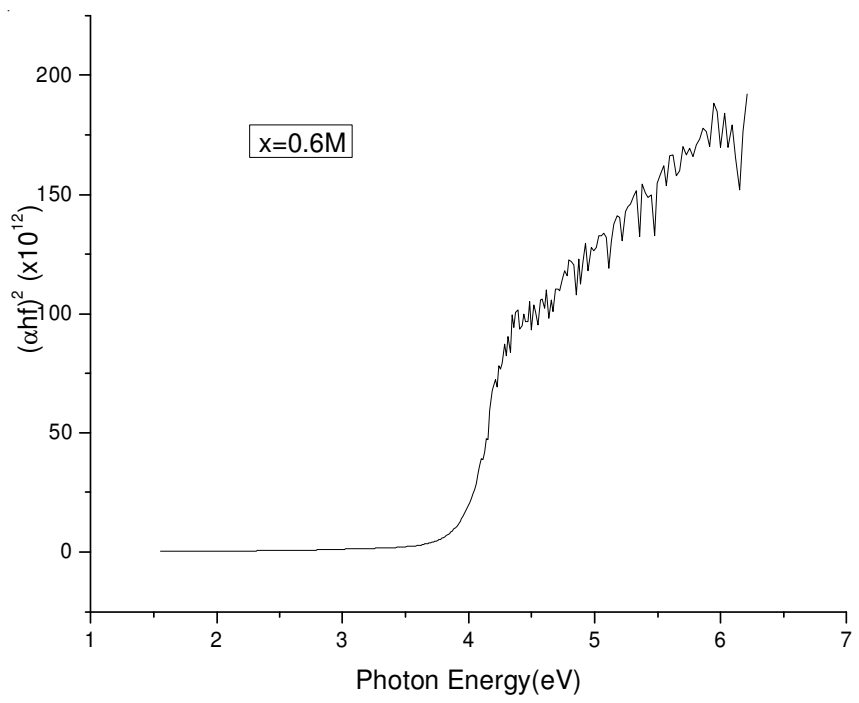

Fig. 4c. Optical energy gap for the direct allowed transition of $\mathrm{SnO}_{2}$ films for the sample prepared by of $0.6 \mathrm{M}$ concentration

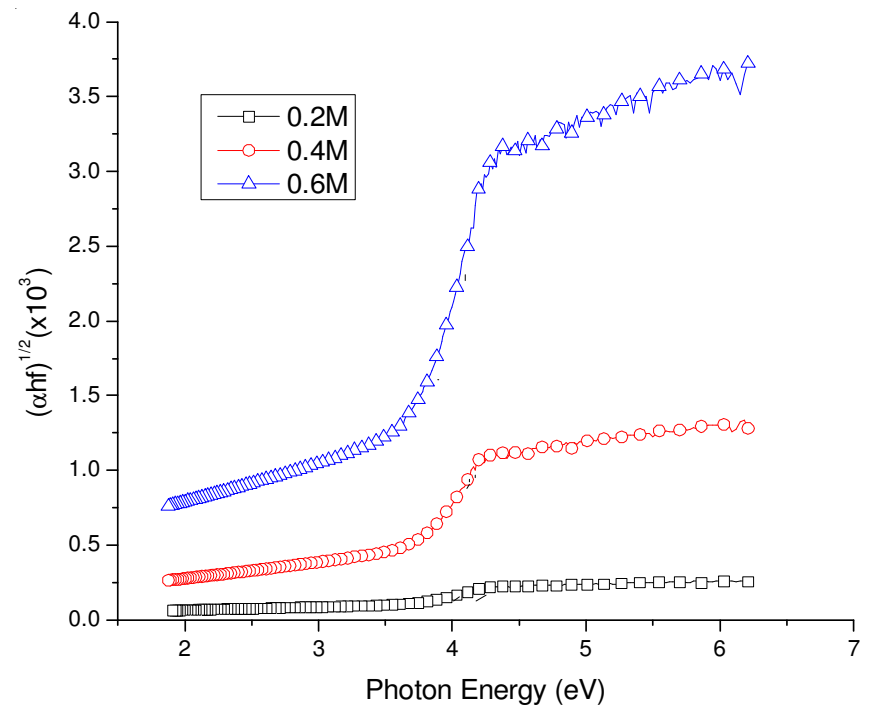

Fig. 5a. Optical energy gap for the indirect allowed transition of $\mathrm{SnO}_{2}$ films for the sample prepared for three concentrations

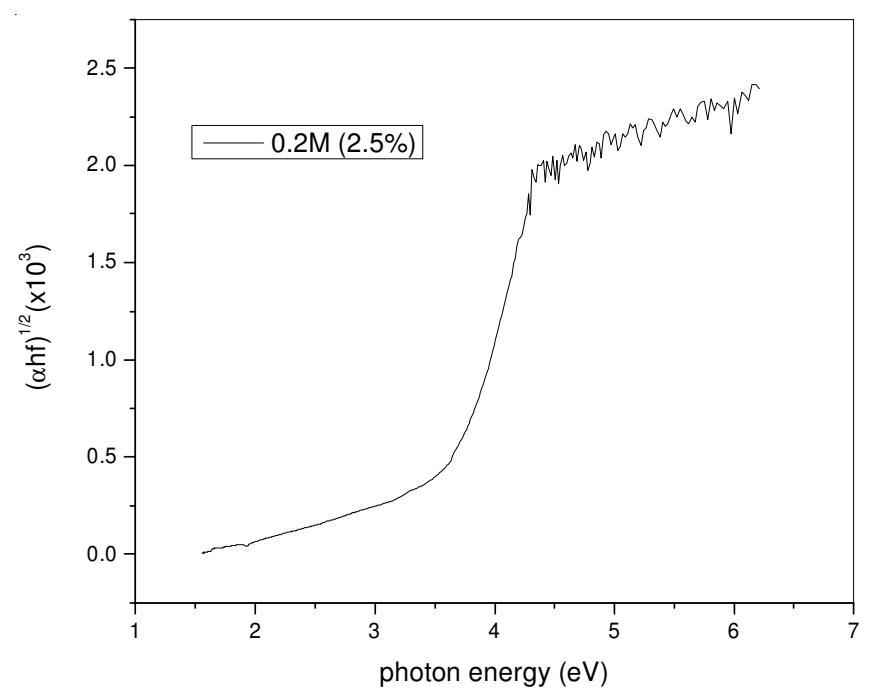

Fig. 5b. Indirect band gap of $\mathrm{Cu}$ doped $\mathrm{SnO}_{2}$

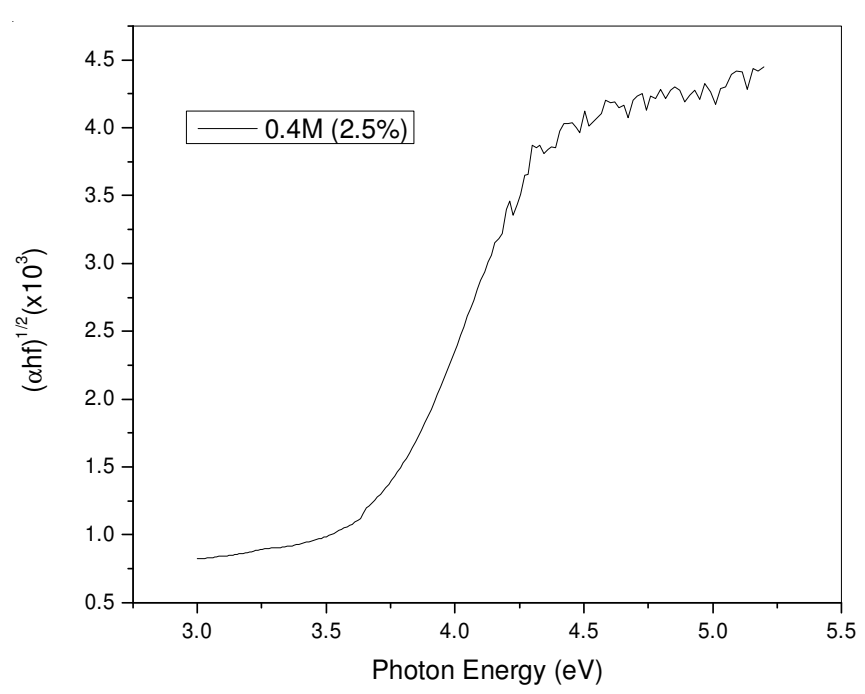

Fig. 5c. Indirect band gap for $\mathrm{Cu}$ doped $\mathrm{SnO}_{2}(0.4 \mathrm{M})$ 


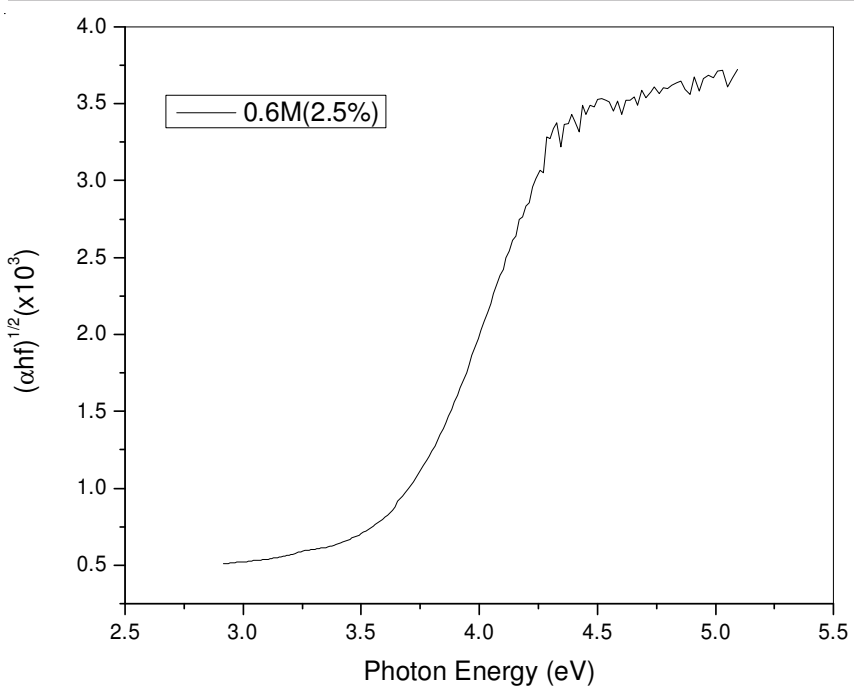

Fig. 5d. Indirect band gap for $\mathrm{Cu}$ doped $\mathrm{SnO}_{2}(0.6 \mathrm{M})$

Figs. 5b-d shows the UV spectra for $\mathrm{Cu}$ doped $\mathrm{SnO}_{2}$ thin films with copper concentration of $2.5 \%$ in $0.2,0.4$ and $0.6 \mathrm{M}$ solutions. From these spectra, it is observed that the indirect energy gap of the thin films decreases as 3.76, 3.73 and $3.16 \mathrm{eV}$, respectively for different concentrations of the precursor solutions. The less value may be due to the addition of $\mathrm{Cu}$ - dopant and may also be due to growth of grain and improvement of the degree of crystallization. As for as direct band gap is concerned that the $\mathrm{Cu}$ doping appears to have no effect on the direct band gap which is in accordance with as reported in the literature [13].

Fig. $6 \mathrm{a}$ and $6 \mathrm{~b}$ show the XRD patterns of tin oxide and $\mathrm{Cu}$ doped tin oxide thin films, respectively. Fig. 6a shows that tin oxide thin films have crystalline nature. The peaks at [101] and [022] planes were present. The peaks corresponding to angles $6.87^{\circ}$ and $13^{\circ}$ was unidentified. The lattice parameters for tin oxide thin films were calculated. It was found that the lattice parameter ' $a$ ' for tin oxide thin films was 6.75 and the value of ' $c$ ' came out to be 4.53 which are different from the values mentioned in the literature. However for $\mathrm{Cu}$ doped tin oxide thin films, the peaks having planes [022] and [101] were examined in Fig. 6b. The peak corresponding to 10.97 was unidentified [8]. The lattice

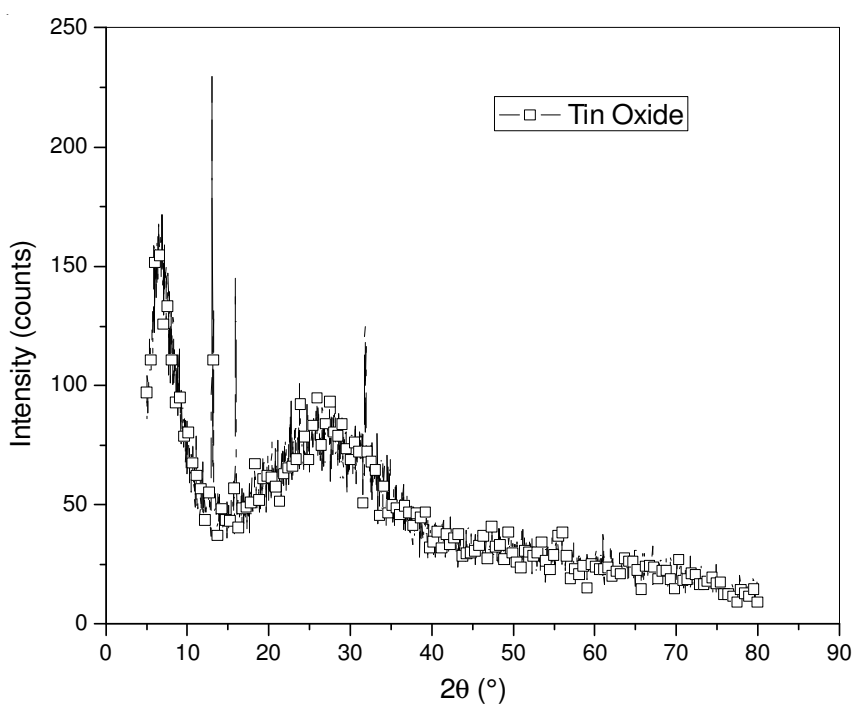

Fig. 6a. XRD spectra of tin oxide thin film prepared with $0.2 \mathrm{M}$ concentration

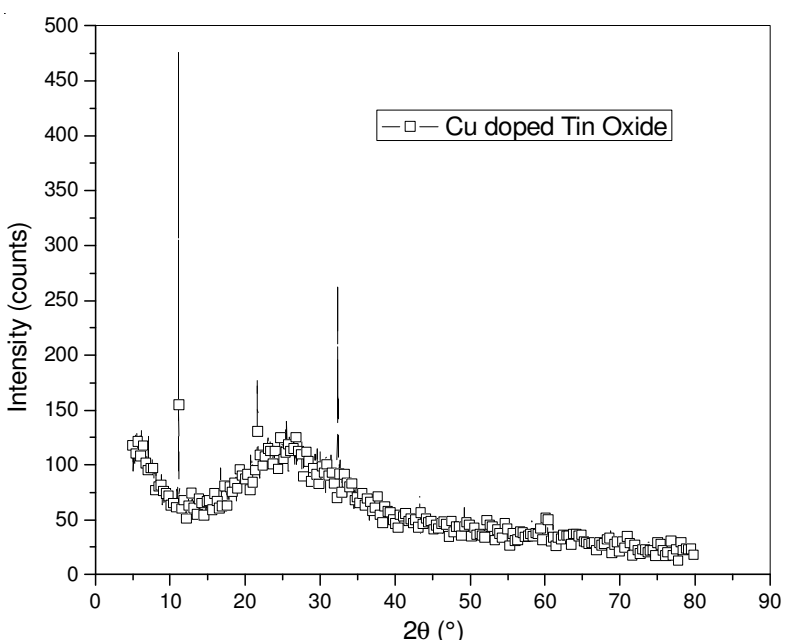

Fig. 6b. XRD spectra of $\mathrm{Cu}$ doped tin oxide thin film prepared with $0.2 \mathrm{M}$ concentration

parameter ' $a$ ' and 'c' for $\mathrm{Cu}$ doped tin oxide thin films were 6.03 and 4.05 , respectively. The tin oxide thin films had tetragonal rutile structure. The calculated XRD parameters for tin oxide and $\mathrm{Cu}$ doped tin oxide thin films are shown in Tables 1 and 2, respectively.

TABLE-1

XRD DATA FOR TIN OXIDE THIN FILMS

\begin{tabular}{cccccc}
\hline hkl & $2 \theta\left({ }^{\circ}\right)$ & $\begin{array}{c}\text { Intensity } \\
(\mathrm{I})\end{array}$ & $\mathrm{d}$ & $\mathrm{a}$ & $\mathrm{c}$ \\
\hline$(101)$ & 15.85 & 145.110 & 5.58 & 7.891311678 & 5.302961448 \\
$(020)$ & 31.73 & 124.078 & 2.81 & 5.62 & 3.77664 \\
\hline
\end{tabular}

TABLE-2

XRD DATA FOR COPPER DOPED TIN OXIDE THIN FILMS

\begin{tabular}{cccccc}
\hline $\begin{array}{c}\text { hkl } \\
\text { values }\end{array}$ & $2 \theta\left({ }^{\circ}\right)$ & $\begin{array}{c}\text { Intensity } \\
(\mathrm{I})\end{array}$ & $\mathrm{d}$ & $\AA$ & $\mathrm{c}$ \\
\hline$(022)$ & 21.73 & 174.679 & 4.085 & 8.16 & 5.48 \\
$(101)$ & 32.25 & 260.447 & 2.772 & 3.92 & 2.63 \\
\hline
\end{tabular}

\section{Conclusion}

Tin oxide thin films have been successfully deposited on the glass substrates by using sol gel spin coating technique. Thin films were fabricated by taking the different concentrations of precursor solutions of tin(IV) chloride dihydrate and copper acetate. From the absorbance spectra, it has been concluded that the absorbance is low and transmittance is high. This is due to the greater thickness of the films which is in $\mu \mathrm{m}$. The prepared thin films have wide energy band gap in the range of 3.77-3.83 eV which is in agreement with the energy band gap values reported in the literature. Due to more absorbance in the UV region and low absorbance in the visible region, these films can be used to stop UV radiations and admit the visible light. These films appear to have potential to be used in optoelectronic devices.

\section{ACKNOWLEDGEMENTS}

The authors sincerely thank the cooperation extended by Mr. Navjot Singh and Mr. Jagtar Singh of Sophisticated Analytical instrumentation Facility (SAIF), Panjab University, Chandigarh for X-ray diffraction studies of the samples. 


\section{REFERENCES}

1. S.K. Tripathy, B.P. Hota and P.V. Rajeswari, Afr. Rev. Phys., 7, 265 (2012)

2. F. Zahedi, R.S. Dariani and S.M. Rozati, Bull. Mater. Sci., 3, 433 (2014); https://doi.org/10.1007/s12034-014-0696-8.

3. K.L. Jarvis and P.J. Evans, Thin Solid Films, 624, 111 (2017); https://doi.org/10.1016/j.tsf.2016.12.055.

4. J.-S. Park, H. Chae, H.K. Chung and S.I. Lee, Semicond. Sci. Technol., 26, 034001 (2011); https://doi.org/10.1088/0268-1242/26/3/034001.

5. S.S. Lekshmy, I.J. Berlin, L.V. Maneeshya, Anitha and K. Joy, IOP Conf. Ser.: Mater. Sci. Eng, 73, 012018 (2015) https://doi.org/10.1088/1757-899X/73/1/012018.

6. F. Gu, S.F. Wang, M.K. Lü, X.F. Cheng, S.W. Liu, G.J. Zhou, D. Xu and D.R. Yuan, J. Cryst. Growth, 262, 182 (2004); https://doi.org/10.1016/j.jcrysgro.2003.10.028.

7. S.-C. Lee, J.-H. Lee, T.-S. Oh and Y.-H. Kim, Sol. Energy Mater. Sol. Cells, 75, 481 (2003);

https://doi.org/10.1016/S0927-0248(02)00201-5.

8. S.K. Tripathy, B.P. Hota and P.V. Rajeswari, Bull. Mater. Sci., 36, 1231 (2013);

https://doi.org/10.1007/s12034-013-0582-9.

9. B. Yarmand, Int. Mater. Phys. J., 2, 20 (2014).
10. M. Marikkannan, V. Vishnukanthan, A. Vijayshankar, J. Mayandi and J.M. Pearce, AIP Adv., 5, 027122 (2015); http://dx.doi.org/10.1063/1.4909542.

11. J.O. Ajayi and D.B. Agunbiade, Int. J. Res. Appl. Sci. Eng. Technol., 3, 821 (2015)

12. A.D. Bhagwat, S.S. Sawant, B.G. Ankamwar and C.M. Mahajan, J. Nano Electron. Phys., 7, 04037 (2015).

13. P.G.L. Baker, R.D. Sanderson and A.M. Crouch, Thin Solid Films, $\mathbf{5 1 5 ,}$ 6691 (2007); https://doi.org/10.1016/j.tsf.2007.01.042.

14. S.K. Tripathy, R. Prabeena, V.S. Jahnavi and N.V.P.R. Thirumala, Int. J. Sci. Res., 2, 101 (2013).

15. E. Savarimuthu, N. Sankarasubramanian, B. Subramanian, M. Jayachandran, C. Sanjeeviraja and S. Ramamurthy, Surf. Eng., 22, 268 (2006); https://doi.org/10.1179/174329406X122838.

16. S. Saipriya, M. Sultan and R. Singh, Physica B, 406, 812 (2011); https://doi.org/10.1016/j.physb.2010.12.003.

17. M. Shaban, G.F. Attia, M.A. Basyooni and H. Hamdy, Int. J. Eng. Adv. Res. Technol., 1, 11 (2015).

18. I.H. Kadhim and H.A. Hassan, J. Appl. Sci. Agric., 10, 159 (2015)

19. S.S. Oluyamo and D.B. Agunbiade, Int. J. Innov. Res. Adv. Stud., 3, 2394 (2016). 